\title{
Effect of commercial medicinal feeds on the physical and chemical properties of urine
}

\author{
Olga Vorontsova ${ }^{1}$, Nikolay Pudovkin ${ }^{1 *}$, Vladimir Salautin ${ }^{1}$, Tatyana Prokhorova ${ }^{1}$, and \\ Andrey Terentyev ${ }^{1}$ \\ ${ }^{1}$ Saratov State Agrarian University named after N. I. Vavilov, 335, Sokolovaya Str., 410005, Saratov, \\ Russia
}

\begin{abstract}
For the study, two groups of cats were formed at the age of 1 to 4 years in the amount of 6 animals each. According to research it was found that cats are more likely to suffer from urolithiasis than cats. At the same time, in the percentage ratio of the difference between castrated and non-castrated cats with urolithiasis, it was not expressed explicitly $(29.01 \%$ and $31.49 \%$, respectively, of the total number of sick animals). The highest percentage of incidence of urolithiasis was recorded in sterilized cats $(23.98 \%)$. It was found that after feeding animals with commercial feed in the studied time there is a decrease in the number of struvites in the urine. The greatest decrease in struvite count was determined after feeding cats with Hills prescription diet urinary care $\mathrm{c} / \mathrm{d}$ multicare. There is also a change in the acid-base state of urine when feeding Hills prescription diet urinary care c/d multicare by $10.9 \%$ and $13.1 \%$ and Hills prescription diet urinary care c/d multicare by $12.3 \%$ and $9.5 \%$ to 3 and 6 months, respectively. Significant differences in urine density after feeding with commercial feed and homemade food have not been established.
\end{abstract}

\section{Introduction}

Currently, only 2 domestic cats out of 10 do not eat commercial food. If these cats are diagnosed with urolithiasis, it is not possible to correct their diet with natural food because of the cat's taste preferences and refusal of natural diets. In turn, the cat food market has a large number of feeds designed for prevention and treatment of urolithiasis.

According to statistics from the American College of Veterinary Internal Medicine, the incidence of struvite (magnesium-ammonium-phosphate) urolithiasis decreased while the incidence of calcium oxalate stones increased in recent years. It should noted that in 1990s the opposite situation was typical: struvite urolithiasis comprised up to $89-90 \%$ of all cases while now its incidence is only $40-50 \%$. The reason for the decrease in the incidence of struvite urolithiasis has not been fully studied, but presumably it can be attributed to the spread of therapeutic and preventive feeds with reduced magnesium content and acidifying properties. Medications do not dissolve calcium oxalates and although diet is considered an important means of preventing urolithiasis, there are very few studies and evidence for this $[1,2,3,4,5]$. The American College of Veterinary Internal Medicine has drafted a plan for

* Corresponding author: niko-pudovkin@yandex.ru 
treatment and prevention of struvite urolithiasis with the help of specific medications and diets.

The method for investigating relative supersaturation (RSS) is based on determining the degree of urine saturation with crystalline compounds. Crystallization occurs due to the release of urolite precursors in a certain form leading to a chemical reaction between them. The concentration of precursor salts must be high for this to occur. The RSS method is time-consuming and expensive, so it is only available for scientific research. The crystallization activity coefficient is calculated and compared with its solubility coefficient value using special software; as a result, the RSS value is obtained.

This study confirms that the use of diets helps dissolve struvites and is a reliable indicator of the dynamics of dissolution of struvite stones [6].

Clinical studies have shown that dilution of urine has a positive effect on the prevention and treatment of urolithiasis. Dilution of urine helps reduce the concentration of precursors $[7,8]$. Dilution of urine is achieved by increasing the frequency of diuresis, thereby reducing the residence time of mineral compounds in the bladder. Most publications suggest diluting the urine concentration by increasing the frequency of diuresis as a preventive measure. It is necessary to dilute the urine to an optimal relative density of 1.030 or lower $[9,10]$.

The body of cats is very specific, thus, if they don't consume much water or if they eat feeds with reduced humidity, their urine becomes highly concentrated with the relative density increasing to 1.065 or higher [11].

One of the most important factors in the prevention of urolithiasis is properly organized feeding of cats that allows you to preserve their health and maintain their strength [12]. Faulty feeding management often leads to serious diseases, exhaustion, and even to the death of animals $[9,13]$.

\section{Materials and Methods}

When conducting statistical studies, we analyzed cases of treatment of owners of cats and cats with a urological syndrome from the age of 6 months. up to 12 years old, of different breeds, types of feeding, and conditions of detention from 2015 to 2019. All animals were treated on an outpatient basis under the supervision of the owners. The subject of the study was the frequency of registration of urolithiasis and idiopathic cystitis in cats and cats, depending on the season, age, physical activity, gender and type of feeding. The data were generated based on outpatient journals and patient histories for 2015 to 2019. inclusive.

The study was performed on the basis of veterinary clinic Powderpill-service (Penza), veterinary clinic Zoo Planet (Zarechny, Penza region), and the FSBEI Saratov State Agricultural University. For the study, two groups of cats aged one to four years were formed, six animals in each.

All animals had been kept completely at home and had mostly been eating dry feed. Clinical examination included urinalysis, and ultrasound examination of the urinary system.

The common urine analysis - on analyzer CL-50 Plus Urine Analyzer (USA), urine density was determined with a refractometer, and urine sediment was examined by microscopic examination directly at the clinic upon animals' admission.

When conducting statistical studies, we analyzed cases of treatment of owners of cats and cats with a urological syndrome from the age of 6 months. up to 12 years old, of different breeds, types of feeding, and conditions of detention from 2015 to 2019. All animals were treated on an outpatient basis under the supervision of the owners. The subject of the study was the frequency of registration of urolithiasis and idiopathic cystitis in cats and cats, depending on the season, age, physical activity, gender and type of feeding. 
The data were generated based on outpatient journals and patient histories for 2015 to 2019 . inclusive.

Digital material was subjected to statistical analysis with calculation of the Student's tcriterion on a personal computer with the standard variation statistics program in Microsoft Excel.

\section{Results}

The first stage of the study was to study the frequency of occurrence of urolithiasis depending on gender (Fig. 1).

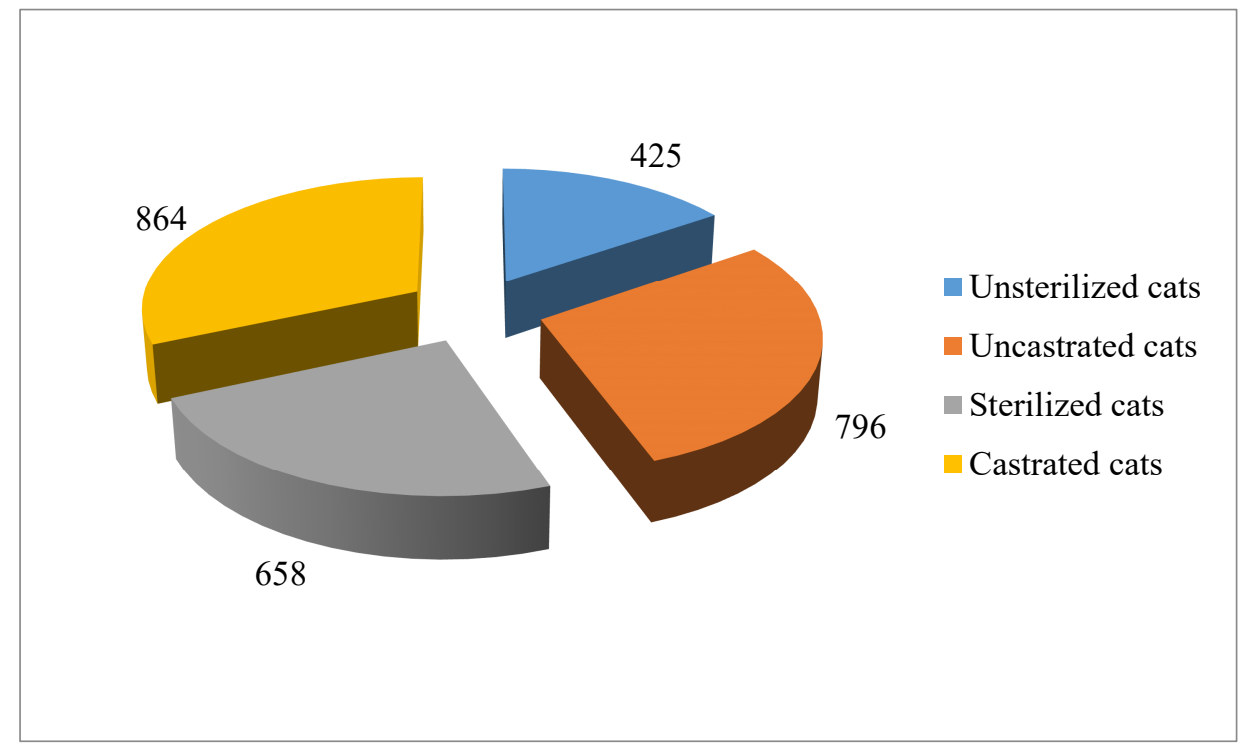

Fig. 1. The frequency of diseases of urolithiasis depending on gender $(n=2743)$.

According to research it was found that cats are more likely to suffer from urolithiasis than cats. At the same time, in the percentage ratio of the difference between castrated and non-castrated cats with urolithiasis, it was not expressed explicitly $(29.01 \%$ and $31.49 \%$, respectively, of the total number of sick animals). The highest percentage of incidence of urolithiasis was recorded in sterilized cats $(23.98 \%)$.

Next, we studied the number of struvites in the urine of cats (Table 1).

Table 1. The number of struvites (pcs) in cat urine depending on various feeds.

\begin{tabular}{|c|c|c|c|}
\hline Duration of feeding & 1 month & 3 months & 6 months \\
\hline $\begin{array}{c}\text { Pro Plan Veterinary Diets } \\
\text { Urinary Cat Food }\end{array}$ & $11.25 \pm 2.14$ & $5.67 \pm 1.66^{*}$ & $2.40 \pm 1.24^{*}$ \\
\hline $\begin{array}{c}\text { Monge VetSolution urinary } \\
\text { struvite }\end{array}$ & $7.14 \pm 1.44$ & $5.00 \pm 2.05^{*}$ & $6.20 \pm 2.01^{*}$ \\
\hline $\begin{array}{c}\text { Royal canin veterinary diet } \\
\text { urinary s/o }\end{array}$ & $9.13 \pm 2.27$ & $5.75 \pm 1.60^{*}$ & $1.71 \pm 0.52^{*}$ \\
\hline $\begin{array}{c}\text { Hills prescription diet urinary } \\
\text { care c/d multicare }\end{array}$ & $14.43 \pm 3.10$ & $6.17 \pm 1.83^{*}$ & $1.33 \pm 0.95^{*}$ \\
\hline $\begin{array}{c}\text { Cheap commercial feeds } \\
\text { (Whiskas. Kitekat. Frieskies) }\end{array}$ & $13.57 \pm 2.39$ & $19.00 \pm 4.00^{*}$ & $2.00 \pm 0.04^{*}$ \\
\hline $\begin{array}{c}\text { Home-cooked food. meat. fish. } \\
\text { poultry. dairy products. Cereals }\end{array}$ & $11.00 \pm 2.87$ & $11.71 \pm 3.42$ & $8.00 \pm 2.52^{*}$ \\
\hline
\end{tabular}


Note: reliability of differences relative to the first month: ${ }^{*}-\mathrm{p} \leq 0,05$

It was found that after feeding the cat with Pro Plan Veterinary Diets Urinary for three and six months, the number of struvites decreased by 2 and 4.7 times compared to the first month. After feeding the cat with Monge VetSolution urinal struvite for 3 and 6 months, the number of struvites decreased by $42.8 \%$ and $15.2 \%$, respectively; in the case of Royal canin veterinary diet urinary s/o the incidence of struvite decreased by $20.6 \%$ and 5.3 times, respectively; in the case of Hills prescription diet urinary care $\mathrm{c} / \mathrm{d}$ multicare the incidence of struvites decreased by 2.3 and 10.8 times, respectively, in relation to the first month. When feeding animals with cheap commercial feeds, the number of struvites increased by $28.6 \%$ by the $3 \mathrm{rd}$ month, but by the 6 th month their concentration decreased by 6.8 times compared to the $1 \mathrm{st}$ month. When feeding cats with homemade food, there were no significant differences in the number of struvites by the $3 \mathrm{rd}$ month, and by the 6 th month their number decreased by $37.5 \%$ relative to the first.

Microscopic analysis revealed that struvites were present in the urine in a sufficiently large amount (Fig.2).

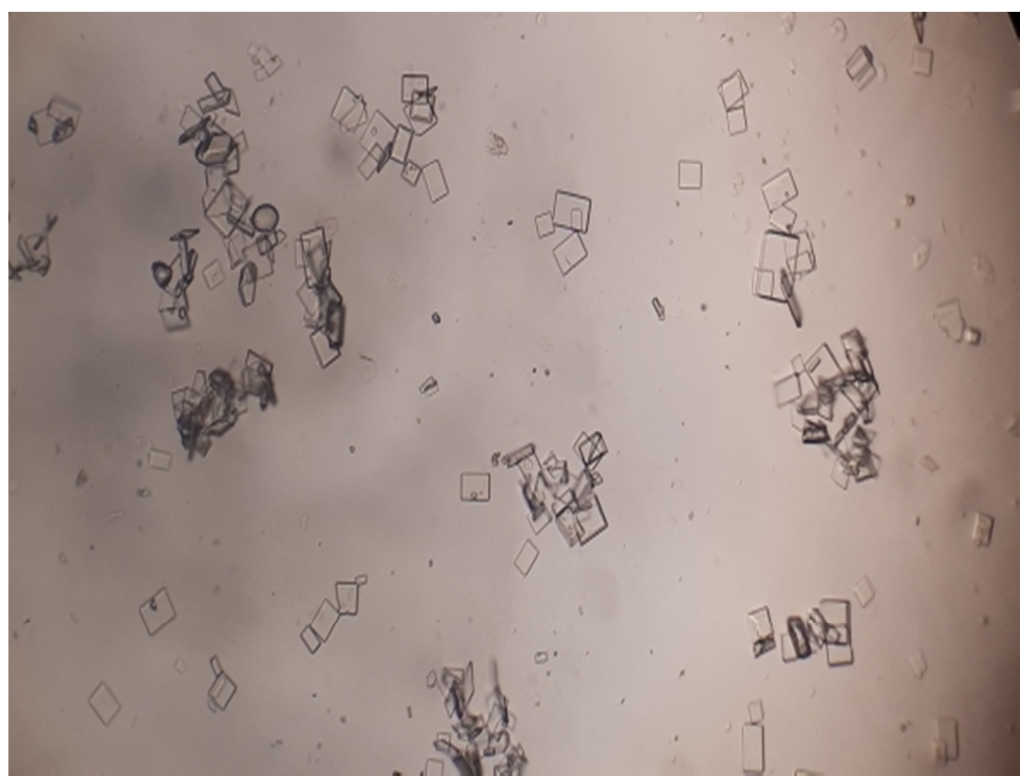

Fig. 2. Struvites in the feline urine before applying Urinary High Dilution.

On the 10th day since the start of feeding therapy, the edges of the struvites become rounded (Fig.3). After applying the feed and providing symptomatic treatment, we found no traces of struvites in the urine (Fig. 4), whereas symptomatic treatment alone resulted in occurence of single struvites. 
Fig. 3. Rounding of the edges of struvites found in feline urine on the 10th day after application of Urinary High Dilution.

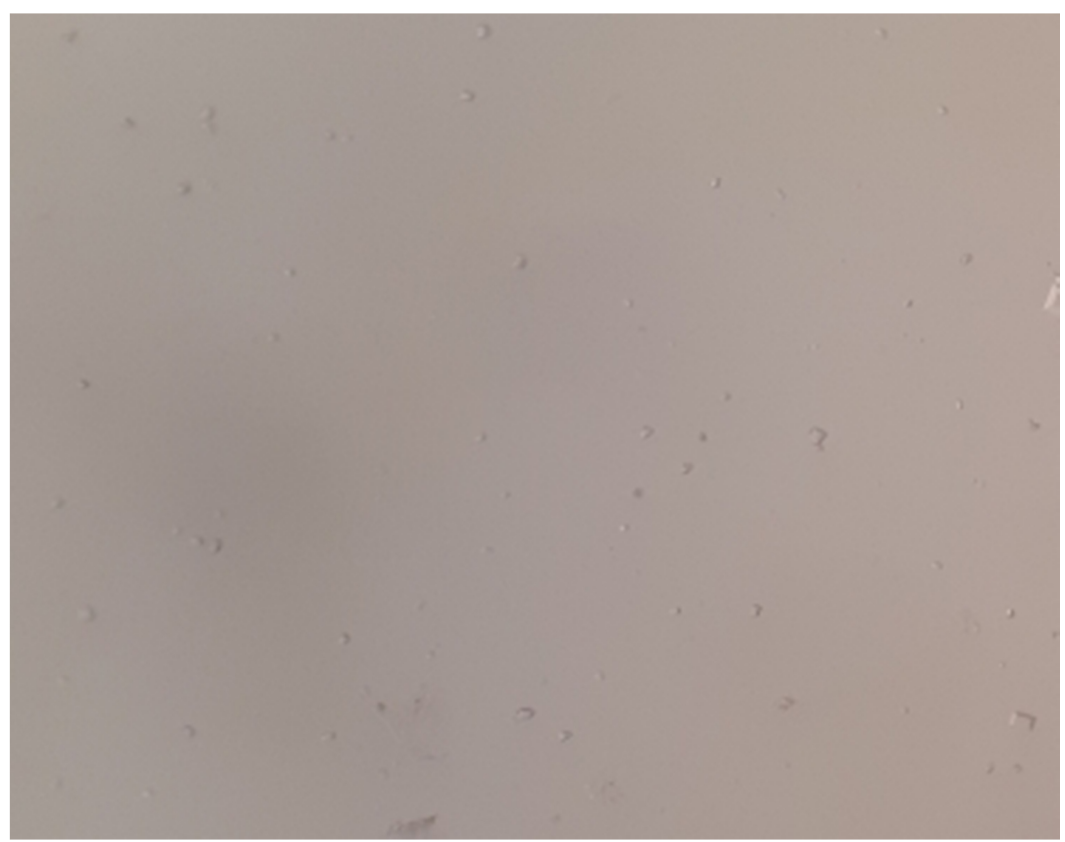

Fig. 4. Results of microscopic analysis of feline urine after application of Urinary High Dilution.

Next, we studied the dependence of feline urine $\mathrm{pH}$ on the type of cat feeds used. The results of this study are presented in table 2 .

Table 2. $\mathrm{pH}$ of urine of cats fed with various feeds.

\begin{tabular}{|c|c|c|c|}
\hline Duration of feeding & 1 month & 3 months & 6 months \\
\hline $\begin{array}{c}\text { Pro Plan Veterinary Diets Urinary } \\
\text { Cat Food }\end{array}$ & $6.81 \pm 0.188$ & $6.50 \pm 0.13$ & $6.30 \pm 0.122$ \\
\hline Monge VetSolution urinary struvite & $6.93 \pm 0.202$ & $6.90 \pm 0.245$ & $6.60 \pm 0.292$ \\
\hline
\end{tabular}




\begin{tabular}{|c|c|c|c|}
\hline $\begin{array}{c}\text { Royal canin veterinary diet urinary } \\
\text { s/o }\end{array}$ & $6.81 \pm 1.188$ & $6.14 \pm 0.21^{*}$ & $6.02 \pm 0.154^{*}$ \\
\hline $\begin{array}{c}\text { Hills prescription diet urinary care } \\
\text { c/d multicare }\end{array}$ & $6.93 \pm 0.170$ & $6.17 \pm 0.105^{*}$ & $6.33 \pm 0.105^{*}$ \\
\hline $\begin{array}{c}\text { Cheap commercial feeds (Whiskas. } \\
\text { Kitekat. Frieskies) }\end{array}$ & $7.14 \pm 0.210$ & $7.10 \pm 0.292$ & $6.50 \pm 0.001$ \\
\hline $\begin{array}{c}\text { Home-cooked food. meat. fish. } \\
\text { poultry. dairy products. cereals }\end{array}$ & $7.06 \pm 0.240$ & $7.7 \pm 0.14$ & $6.75 \pm 0.144$ \\
\hline
\end{tabular}

Note: reliability of differences relative to the first month: * $-\mathrm{p} \leq 0,05$

According to our, the only feeds that significantly changes the acid-base balance of urine are Hills prescription diet urinal care c/d multicare that leads to urine $\mathrm{pH}$ decreasing by $10.9 \%$ (after 3 months) and 13.1\% (after 6 months), respectively, and Hills prescription diet urinal care $\mathrm{c} / \mathrm{d}$ multicare that leads to $\mathrm{pH}$ decreasing by $12.3 \%$ (after 3 months) and $9.5 \%$ (after 6 months), respectively, relative to the initial values. In other cases, no significant differences were found. Changing the $\mathrm{pH}$ of urine through dietary modification or medication can be a very effective way to treat some (but not all) types of urolithiasis.

The results of studies on the effect of various feeds on the feline urine density are presented in table 3 .

Table 3. Density of urine of cats fed with various feeds.

\begin{tabular}{|c|c|c|c|}
\hline Duration of feeding & 1 month & 3 months & 6 months \\
\hline $\begin{array}{c}\text { Pro Plan Veterinary Diets } \\
\text { Urinary Cat Food }\end{array}$ & $1.050 \pm 0.00$ & $1.050 \pm 0.003$ & $1.040 \pm 0.003$ \\
\hline $\begin{array}{c}\text { Monge VetSolution urinary } \\
\text { struvite }\end{array}$ & $1.050 \pm 0.002$ & $1.050 \pm 0.004$ & $1.050 \pm 0.003$ \\
\hline $\begin{array}{c}\text { Royal canin veterinary diet } \\
\text { urinary s/o }\end{array}$ & $1.050 \pm 0.001$ & $1.050 \pm 0.001$ & $1.040 \pm 0.002$ \\
\hline $\begin{array}{c}\text { Hills prescription diet urinary } \\
\text { care c/d multicare }\end{array}$ & $1.050 \pm 0.001$ & $1.050 \pm 0.001$ & $1.050 \pm 0.002$ \\
\hline $\begin{array}{c}\text { Cheap commercial feeds } \\
\text { (Whiskas. Kitekat. Frieskies) }\end{array}$ & $1.050 \pm 0.001$ & $1.050 \pm 0.001$ & $1.050 \pm 0.001$ \\
\hline $\begin{array}{c}\text { Home-cooked food. meat. fish. } \\
\text { poultry. dairy products. cereals }\end{array}$ & $1.050 \pm 0.001$ & $1.050 \pm 0.001$ & $1.050 \pm 0.001$ \\
\hline
\end{tabular}

Note: $\mathrm{M} \pm \mathrm{m}$ means average value and its error

There were no significant differences in the effect of commercial feeds on the density of urine of cats diagnosed with urinary system diseases.

Thus, in the course of the our study, we found that the number of struvites in the urine decreases after the animals were fed with commercial feeds for specified periods. The greatest reduction in the number of struvites was caused by Hills prescription diet urinary care $\mathrm{c} / \mathrm{d}$ multicare. We also observed that feeding the cats with Hills prescription diet urinal care $\mathrm{c} / \mathrm{d}$ multicare decreased the urine $\mathrm{pH}$ by $10.9 \%$ (after 3 months) and $13.1 \%$ (after 6 months), while feeding them with Hills prescription diet urinal care $\mathrm{c} / \mathrm{d}$ multicare decreased urine $\mathrm{pH}$ by $12.3 \%$ (after 3 months) and $9.5 \%$ (after 6 months), respectively. There were no significant differences in urine density between the cats who were fed commercial feeds and those who were fed home-cooked food.

The highest percentage of incidence of urolithiasis was recorded in sterilized cats (23.98\%). Animals living in apartments and not having access to the street more often suffer from urolithiasis $(67.88 \%)$, respectively, of the total number of cases) compared with animals on a self-walk. 


\section{Discussion}

Acidification of the urine greatly increases the solubility of struvites and promotes the dissolution of the uroliths formed by them. Alkalinisation of the urine, on the contrary, increases the solubility of urate and cystine uroliths. The effectiveness of diet therapy usually increases if it is possible to reduce the excretion of crystalloids involved in the formation of urolites into the urine [14].

Feeding and watering schemes that help to reduce the concentration of urine are designed to dissolve urolites and reduce further growth and formation of urinary stones by reducing the saturation of urine with inorganic substances from which they are formed. Diets that lower the $\mathrm{pH}$ of urine are useful for the prevention of struvite urolites, but they should not be given to cats with urate stones.

There are 4 most common types of urolites found in the case of urolithiasis - urolites formed by ammonium magnesium phosphate (struvites, triple phosphates), calcium oxalate, ammonium urate, and cystine [15].

\section{References}

1. V.R. Gomes, P.C. Ariza, N.C. Borges, F.J. Schulz, M.C.S. Fioravanti, Veterinary Research Communications 42(1), 87-94 (2018) DOI: 10.1007/s11259-018-9710-8

2. J.C. Parambeth, A. M. Hernandez M.B. Nabity, K.E. Russell, A.N. Myers, M.L. Puchot, K.E. Creevy, J.A. Lidbury, Veterinary Clinical Pathology 47(3), 507-508 (2018) DOI.10.1111/vcp.12622

3. X. Li, W. Wang, Y. Su, Ren Fal 39, 120-129 (2017)

4. P.K. Goyal, S.K. Verma, A.K. Sharma, Phytopharmacol 6, 149-55 (2017)

5. S. Murwani, American Journal of Animal and Veterinary Sciences 11(1), 47-54 (2016) DOI:10.3844/ajavsp.2016.47.54

6. O.A. Vorontsova, T.I, Shutova, N.A. Pudovkin, T.M. Prokhorova, P.V. Smutnev, I.G. Subbotin, Pharmacophore 10(6), 31-36 (2019)

7. A.K. Martusevich, L.M. Kozlova, Iraqi Journal of Veterinary Sciences 31(1), 23-27 (2017) DOI:10.33899/ijvs.2017.126706

8. P.E. Taksande, N.S. Saini, J. Mohindroo, Tarunbir Singh, A. Kumar, Indian Journal of Animal Research 51, 296-302 (2017) DOI:10.18805/ijar.8422

9. B. Balázs, N. Tibor Magyar Allatorvosok Lapja 137(5), 305-313 (2015)

10. L.V. Athanasiou, P.D. Katsoulos, E.G. Katsogiannou, Z.S. Polizopoulou, M. Diamantaki, C. Kamatsos, G. Christodoulopoulos, Veterinary Clinical Pathology 47(2), 284-288 (2018) DOI.10.1111/vcp.12581

11. B. Gerber, F. Brandenberger-Schenk, E. Rothenanger, C. Müller, Schweizer Archiv fur Tierheilkunde 158(10), 711-716 (2016) DOI: 10.17236/sat00089

12. T. Oxge Yaarand, K. Ozkan, Indian Journal Of Animal Research 51, 1157-1158 (2017) DOI:10.18805/ijar.v0iOF.7610

13. L.A. Poore, R. Hendry, J. Steyl, S. Pfitzer, Journal of the South African Veterinary Association 88, 1536 (2017)

14. J. Del-Ángel-Caraza, C.C. Pérez-García, I.A. Quijano-Hernández, C.I. MendozaLópez, I. Diez-Prieto, J.S. Martinez-Castañeda, Veterinaria Mexico 43(4), 317-325 (2012)

15. J.W. Bartges, A.J. Callens, Small Animal Practice 45(4), 747 - 68 (2015) 